\title{
Continuity and Change in Coos County Results from the 2010 North Country CERA Survey
}

\author{
CHRIS R. COLOCOUSIS AND JUSTIN R. YOUNG
}

\section{Introduction}

$\tau$ n 2007, the Carsey Institute began a project to track social and economic change in the North Country, a region along the Canadian border in northeastern Vermont, northern New Hampshire, and western Maine. A Carsey brief focused on Coos County, $\mathrm{NH}$ presented survey results that painted a picture of a rural region in the thick of economic restructuring in the pulp and paper industry, its traditional economic base. ${ }^{1}$ In a continuation of the industry's recent instability, the last remaining mill in the county was idled indefinitely in 2010 and sold, though it was scheduled to resume production in mid2011. In the summer of 2010, the Carsey Institute returned to the North Country to once again assess the state of the region. Residents of Coos County, NH, Oxford County, ME and, for the first time, Essex County, VT were surveyed by telephone as part of the ongoing Community and Environment in Rural America (CERA) study. ${ }^{3}$ The responses of more than 1,800 residents detail their perspectives on their communities, including the extent of economic and environmental concerns, as well as levels of social cohesion and outlooks on the future. Below, we present results from the most recent North Country CERA survey, first focusing on change and continuity in Coos County between 2007 and 2010 before making comparisons of present conditions across our three study counties.

\section{Community Problems}

The economic challenges of the past few years are visible in the 2010 survey data, with more residents concerned about a lack of jobs than in 2007. Perhaps unsurprisingly given the continued economic disruptions of the past few years, a lack of job opportunities again emerged as the primary problem facing Coos communities as shown in Figure 1. In 2010, 96 percent of respondents saw the issue as a problem in their community, up nearly 6 percentage points from 2007 . While concern about the local economy was almost universal in both years, some striking changes have taken place in terms

\section{Key Findings}

- Coos County residents remain highly concerned about the lack of economic opportunities in the region, and concern about population decline has increased in recent years.

- As the loss of forest-based jobs has continued, support for using resources to create jobs has increased, while perceptions of conservation laws have become less positive.

- Despite declining economic circumstances, most Coos residents plan to stay in the region and remain attached primarily to its quality of life, natural beauty, recreational opportunities, and proximity to family.

- Levels of trust and cohesion remain high, though confidence in local government has waned since 2007.

- Coos residents see the economic future of their communities primarily tied to both recreation and traditional forest-based industries, though residents have become somewhat more polarized with respect to levels of support for economic development versus environmental protection.

- North Country residents see the encouragement of new business as a greater priority than preserving the traditional character of their communities.

of related issues Coos residents see as problematic. In the most pronounced shift, far more respondents in 2010 (74 percent) than 2007 (53 percent) saw population decline as a local problem. This higher prevalence of concern corresponds to actual demographic conditions in the county, the population of which declined by one-and-a-half percent 
over this three-year span, from 32,317 to 31,487 , continuing a decades-long trend. ${ }^{4}$ As population decline is now viewed as problematic by a greater percentage of residents, concern over a lack of affordable housing has declined slightly (from 48 to 41 percent), though this shift is not statistically significant, and is likely tied as much to national declines in housing values as it is to regional population trends.

FIGURE 1. "DO YOU CONSIDER THE FOLLOWING TO BE IMPORTANT PROBLEMS FACING YOUR COMMUNITY TODAY?”

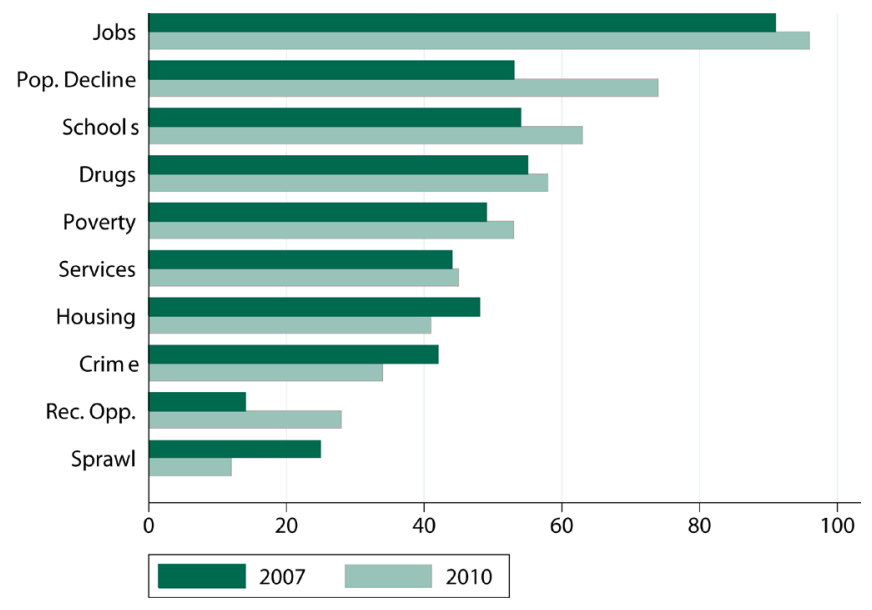

In 2010, just as in 2007, a majority of Coos residents saw the quality of local schools and the manufacture/sale of illegal drugs as community problems, though these perceptions were less widespread than those around jobs or population decline. The level of concern for both of these issues was higher in 2010 than 2007, but only the increase in concern over poor schools (from 54 to 63 percent) was statistically significant. For several other concerns raised by Coos residents, continuity, rather than change, appears to be the rule. Despite increased concern about the local economy, the percentage of residents perceiving poverty/homelessness or a lack of health/ social services to be problems in their community remained essentially unchanged at about 50 and 44 percent, respectively. However, concern about violent or property crime actually fell from 42 to 34 percent between 2007 and 2010.

Just as they were in 2007, respondents in the most recent survey were least likely to cite sprawl and a lack of recreational opportunities as problems, which is not surprising in a region endowed with substantial natural amenities yet experiencing population decline. However, the relative importance of these two issues essentially reversed between 2007 and 2010. In 2007, 25 percent of Coos residents saw sprawl as a problem in their community, while 14 percent saw a lack of recreational opportunities as a problem. In 2010, however, these figures were 12 and 28 percent, respectively. While this decline in the perception of sprawl as a community problem is consistent with the larger story of continued economic and demographic decline, the factors underlying the increase in concern about a lack of recreational opportunities are less clear. Nonetheless, a lack of recreational opportunities remains one of the least widely perceived problems in the county.

\section{Environmental and Economic Concerns}

We asked respondents about a number of environmentrelated issues that many rural communities are faced with, and their perceptions of the effects these issues are having on their community are depicted in Figure 2. With the continued decline of the pulp and paper industry, the percentage of respondents who saw the loss of forest-based jobs as having major community effects increased significantly, from 60 to 67 percent. While concern about forest-based job loss has increased, concern about other environmental issues associated with economic or residential development has declined or remained constant. In 2007, 25 percent of residents saw sprawl or development of the countryside as having major local effects. In 2010, this figure was down to 11 percent, a change consistent with the concerns about economic stagnation in the region. In this largely forested region, concern about the conversion of farmland was essentially unchanged from 2007 to 2010 . However, in 2010 the perceived community effects of farmland conversion are more pronounced than those of sprawl or development more generally.

Figure 2. "COMmunity Impacts of ECONOMic AND ENVIRONMENTAL IsSUEs"

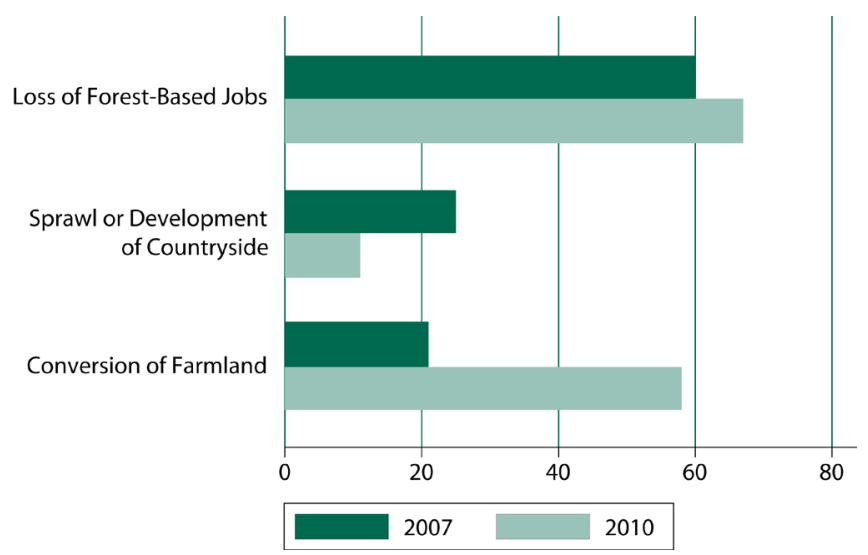

No doubt related to the current economic situation in the region and beyond, support for using natural resources to create jobs has increased significantly in recent years as shown in Figure 3. In 2007, 28 percent of Coos residents said resources should be used for job creation, but just three years later 39 percent took this position. At the same time, support for conserving natural resources for future generations has remained essentially unchanged at roughly 40 percent. The increase in 
the percentage favoring job creation over conservation was offset by a decline in the size of the group who saw job creation and conservation as equal priorities, which went from 31 to 23 percent. Together these results suggest a mild though real increase in the extent of polarization in the county when it comes to support for economic development as opposed to environmental protection. Respondents' attitudes toward zoning laws-here, including rules aimed at conservation or restricting development-appear to reflect this shift in outlook. In 2007, 47 percent of respondents said such regulations have been a good thing in their community, but in 2010 that figure was down to 38 percent.

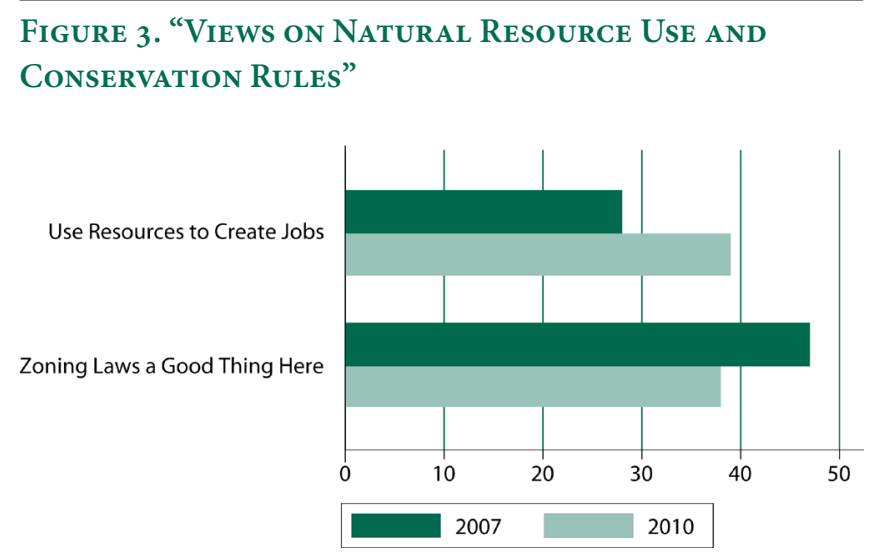

\section{Economic Well-Being and Outlook on the Future}

Respondents were also asked whether they were better off financially today compared to five years ago; responses to this question are shown at the bottom of Figure 4. In 2007, 30 percent of Coos respondents said they were worse off. By 2010 that number had climbed to 45 percent. Less than a quarter stated they are better off financially, while a third said their financial situations remained the same. When compared to neighboring counties, where financial woes are also on the rise, the situation appears more serious in Coos; 38 percent of respondents in Oxford and 35 percent in Essex reported being worse off financially than they were five years prior.

In 2010, Coos residents of all income groups were more likely than in 2007 to report that they were worse off financially. However, in 2010 respondents with annual household incomes under $\$ 40,000$ (51 percent) and those with incomes between $\$ 40,000$ and $\$ 90,000$ (48 percent) were much more likely than those with incomes over $\$ 90,000$ (24 percent) to report being worse off. Indeed, almost half (43 percent) of those with incomes greater than $\$ 90,000$ reported that they were actually better off than they were five years prior. These differences suggest that recent economic disruptions have been felt more acutely at the middle and lower rungs of the socioeconomic spectrum. However, it is likely that house- hold income in 2010 is in large part the result of household economic change between 2007 and 2010. For example, many respondents with household incomes below $\$ 40,000$ in 2010 may have had higher incomes in 2007 (with the opposite the case at the high end of the income spectrum). Such respondents would likely report being worse off, but while they appear in the low end of the income scale in 2010 they were not there in 2007. Because of this, the findings above should be interpreted with caution.

Figure 4. "Economic Well-Being and Expectations For The Future"

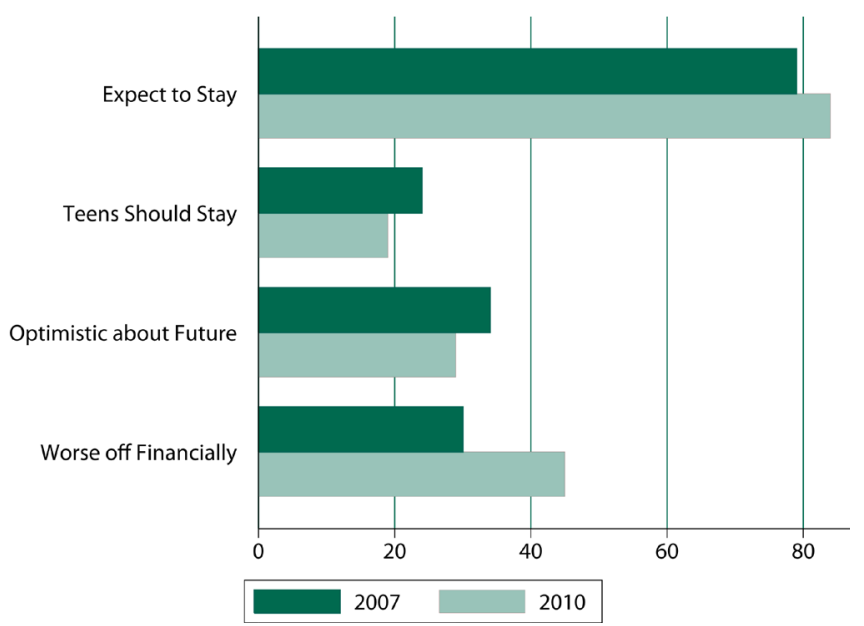

Given the economic challenges now facing the region, it is remarkable that the percentage of Coos respondents that said they planned to remain in the area over the next five years actually increased from 78 to 85 percent (though this is not a statistically significant difference). However, this apparent commitment to place should be interpreted with caution, as this increased percentage may be an artifact of population loss in recent years-many of the "leavers" have in fact already left. Nonetheless, Coos residents remain largely attached to their communities, and just as in 2007, the primary considerations in their decisions to stay are the quality of life, natural beauty, recreational opportunities the region affords, and proximity to family. Recent economic circumstances appear to be related to whether or not respondents plan on remaining in the area. Sixty-four percent of those who expect to leave the area said they were worse off financially than they were five years prior. By contrast, only 40 percent of "stayers" reported being worse off.

As manufacturing jobs continue to disappear and economic uncertainty lingers, Coos residents are looking warily toward the future of their communities, though they tend to anticipate more continuity than change. While it is not a statistically significant decline, residents in 2010 were slightly less hopeful that their community will be a better place to live in ten years (29 percent) compared to three years ago (33 percent). However, this is not to suggest that they feel 
it will necessarily be a worse place to live; the percentage of respondents who were pessimistic about the future of their communities also fell, from 23 to 17 percent. Just as in 2007, the most common response to our question about the future of respondents' communities was that it would be about the same. However, between 2007 and 2010 this figure increased from 43 to 55 percent. Today a majority of Coos residents see their hometowns as remaining basically the same over the next decade. Those who expected to leave, however, were far less optimistic than those who expect to remain in the area. Those indicating plans to leave (we were unable to collect data on leavers' potential destinations) were more than three times as likely to feel that their community will be a worse place to live (37 percent, compared to 12 percent of those who plan to stay). We also asked if respondents would advise a local teenager to remain in or leave their community for opportunity elsewhere. Just as in 2007, a minority (19 percent) of Coos residents would advise a teen to stay. However, nearly 69 percent of those who would advise a teen to leave went on to say they hoped that these teens would return to the area in the future to raise families of their own.

\section{Community Cohesion and Confidence in Local Government}

As is largely the case with respect to community attachment, measures of civic culture remain relatively high in Coos when compared to other rural places, ${ }^{5}$ though recent economic changes appear to have had a modest negative effect in the past few years as shown in Figure 5. The percentage of respondents answering affirmatively when asked if people in their community are willing to help their neighbors was essentially unchanged at 94 percent, as was the percentage who thought people in their community can work together effectively to solve problems, albeit somewhat lower at roughly 80 percent. However, the percentage agreeing that people in their community generally trust each other and get along declined from 91 to 86 percent. Driving this decline in perceived trust was a pronounced shift in perception among respondents with annual household incomes below $\$ 40,000$. The percentage of these respondents who agreed that people generally trust one another and get along fell significantly, from 88 percent in 2007 to 73 percent in 2010. This apparent drop may reflect tensions or frustrations stemming from this group's increasingly disadvantaged economic position, or it may be an artifact of income-related residential patterns such that lower-income respondents were more likely than others to live in communities where levels of trust fell. However, data limitations do not allow these or other potential hypotheses to be tested here.

Compared to community trust and cohesion, confidence in local government presents a different story. This indicator saw the sharpest overall decline among those related to civic life in Coos. In 2007 perspectives were decidedly
Figure 5. "Civic Culture and Confidence in local GOVERNMENT"

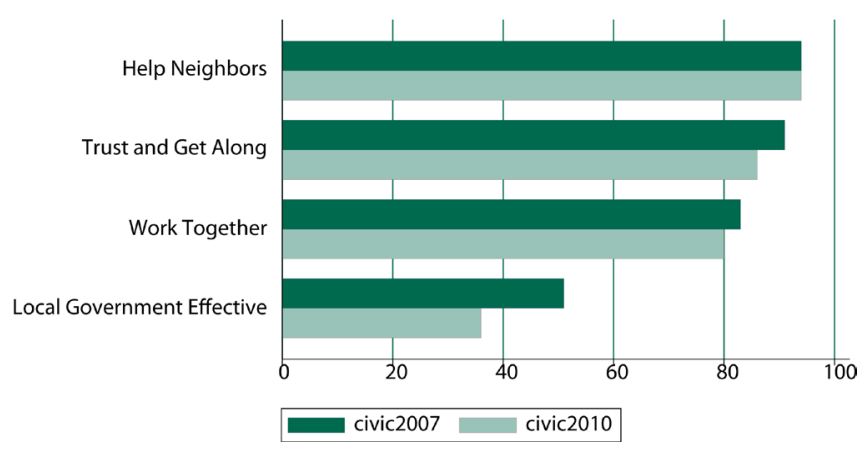

mixed, with 51 percent reporting that their local government could effectively deal with important problems. But in 2010, only 36 percent of respondents agreed their local government could do so (neighboring Oxford county saw a similar decline, from 58 to 39 percent). While the survey data do not allow specific explanations for this drop to be explored, it is possible that this decline in confidence in local government reflects frustration with the United State's current economic slowdown. While comparisons over time are not available, in 2010 only 20 percent of Coos residents said that government can be trusted to do what's right some or most of the time. On the whole, however, trust and cohesion remain relatively high in Coos, with local government's perceived ability to deal with problems being the exception.

\section{The Future of the North Country Economy}

North Country residents in all three study counties see the economic future of their community resting on both traditional forest-based industries such as logging and forest products, which continue to decline, and a recreation-based economy that draws visitors to the area. However, some notable differences exist between the counties. Eighty-three percent of Coos respondents said that the development of tourism and recreation were very important to the future of their community, while 73 percent said that traditional forest-based industry remained very important. Perceived importance of both forms of economic development was significantly higher in Coos than neighboring Oxford (65 percent for traditional forest-based industry, 64 percent for tourism/recreation), with Essex County (68 percent for forest-based, 71 percent for tourism/recreation) somewhere in between.

However, the future of the North Country economy may rest not only on its waning forestry industry or the tourism and recreation that draws on the natural beauty of the area, but also on the utilization of renewable energy resources. Whether in response to regional economic decline, climate- 
change related concerns, or both, communities across rural America are beginning to harness alternative sources of energy. Attitudes in the North Country reflect the growing emphasis that rural populations are beginning to place on these renewable resources. Though not as high a figure as that for traditional forest-based industry or tourism, a majority across the region (55 percent in each county) saw windpowered electricity generation as very important for the economic future of their community. While the perceived importance of wind development is identical in all three counties, that of wood-fired biomass power development differs significantly from place to place. In Coos, where there are pending proposals for new biomass generating stations, a majority (51 percent) saw this form of development as very important for the future. However, in Oxford this figure was only 39 percent, and in Essex it was 46 percent. See Figure 6.

FigURE 6. "HOW IMPORTANT DO YOU THINK THE FOLLOWING FORMS OF ECONOMIC DEVELOPMENT ARE FOR YOUR COMMUNITY'S FUTURE?"

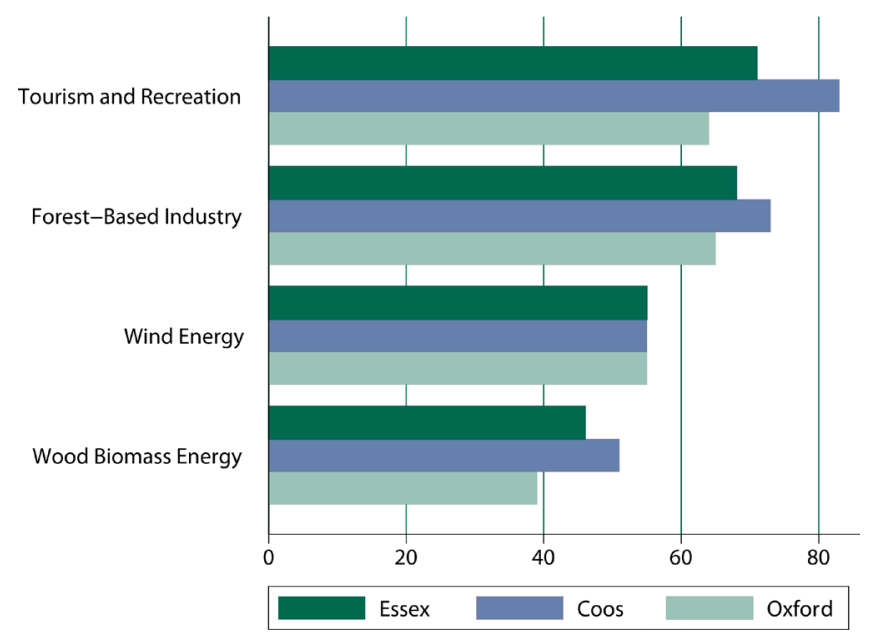

Across the North Country, residents generally viewed the encouragement of economic development (60 percent), as opposed to preserving the traditional character of their communities (40 percent), as the main priority for local government. But again, significant differences exist from county to county. In Coos, where recent economic disruptions have been more pronounced, 66 percent said local government's priority should be economic development. In Oxford, by contrast, this figure was 56 percent. While these differences likely reflect recent economic disruptions as outlined above, and the perceived need for economic development, they may also reflect the extent to which residents commute to jobs outside the area in which they live, and can thus afford to value preservation over local business development in their home communities.

\section{Conclusion}

The data presented here provide an initial glimpse of continuity and change in Coos County and the broader North Country from 2007 to 2010. Challenges stemming from the economic restructuring of the past decade have been deepened by the most recent recession, and issues of limited economic opportunities, financial hardship, and population decline have become more pronounced. Given these trends, it is not surprising that residents' priorities have shifted toward job creation rather than the conservation of natural resources. However, the extent to which North Country residents remain attached to their communities in the face of this economic context is noteworthy, as is the robustness of civic culture in the region's communities. In Coos, recreation and tourism are seen as crucial for the area's economic future. At the same time, residents also value traditional forest-based industries like logging, and to a slightly lesser extent the development of renewable energy resources, reflecting the crucial point of transition at which the region finds itself. As the North Country moves into the future, one of its primary challenges will be working out a balance between what can sometimes be conflicting demands on the region's substantial natural resources. Further change in these dynamics, as well as in the circumstances of the region's residents, is certain to unfold in the years ahead.

\section{Data}

The survey was administered by telephone to 1,852 adults (18 years and older) in Essex (VT), Coos (NH), and Oxford (ME) counties by the UNH Survey Center in June 2010, using random digit dialing (1,825 land lines and 27 cellular phones were reached). The total number of interviews in each of these counties was 345,755 , and 752 , respectively. Sixty percent of respondents were female; 70 percent were age 50 or older. Ninety-six percent of respondents were non-Hispanic white, two percent were Native American, and other categories comprised the remaining two percent of the sample. Data were weighted to correct for potential sampling biases on the basis of age, sex, or race/ethnicity by deriving weights from an age/sex/race population profile of the region based on 2009 Census Population Estimates data (a maximum weighting factor was established to avoid unusual cases unduly influencing overall figures). The maximum margin of error ( 95 percent CI) for percentages reported at the regional level was $+/-2.3$ percentage points. At the county level, it is +/-5.1 in Essex, and +/-3.5 in both Coos and Oxford. Reported between-group and between-year differences are statistically significant (meaning that they are unlikely to have occurred by chance) at the .05 level unless otherwise indicated. 


\section{E N D N O T E S}

1. See Chris Colocousis, "The State of Coos County: Local Perspectives on Community and Change," Issue Brief No. 7 (Durham, NH: Carsey Institute, 2007).

2. Barbara Tetrault, "Sale of Gorham Mill Finalized," Berlin Daily Sun, May $17^{\text {th }} 2011$, accessed May $17^{\text {th }} 2011$, http:// www.berlindailysun.com/featured/story/sale-gorham-millfinalized.

3. See http://carseyinstitute.unh.edu/CERA/cera-home.html.

4. U.S. Census Bureau Annual Estimates of the Resident Population by Selected Age Groups and Sex for Counties: April 1, 2000 to July 1, 2009.

5. See Lawrence C. Hamilton et al., Place Matters: Challenges and Opportunities in Four Rural Americas, A Carsey Institute Report on Rural America (Durham, NH: Carsey Institute, 2008).

\section{A UTHORS}

Chris R. Colocousis is an assistant professor of sociology at James Madison University and a faculty fellow at the Carsey Institute (colococr@jmu.edu).

Justin R. Young is a graduate student in the Department of Sociology at the University of New Hampshire and a research assistant at the Carsey Institute (jrobertyoung@gmail.com).

\section{A C K N O W LE D G M E N T S}

The authors would like to thank Amy Sterndale and Curt Grimm of the Carsey Institute and Pamela Laflamme, Berlin City Planner, for their thoughtful comments and suggestions.

\section{UNIVERSITY A. of NeW HAMPSHIRE}

\section{CARSEY}

Building knowledge for families and communities

The Carsey Institute conducts policy research on vulnerable children, youth, and families and on sustainable community development. We give policy makers and practitioners timely, independent resources to effect change in their communities.

Carsey Institute Reports on Tracking Change in the North Country are supported by the Neil and Louise Tillotson Fund at the New Hampshire Charitable Foundation and the Carsey Institute endowment.

Huddleston Hall

73 Main Street

Durham, NH 03824

(603) 862-2821

www.carseyinstitute.unh.edu 